OAI-PMH: http://www.indteca.com/ojs/index.php/Revista Scientific/oai

Ensayo Original / Original Essay

\title{
Teoría Educativa desde el Paradigma de la Complejidad para Formar Pensamiento Crítico y Complejo
}

\author{
Autor: Ángel Yasmil Echeverría Guzmán \\ Universidad Latinoamericana y del Caribe, ULAC \\ angelecheverria71@gmail.com \\ Caracas, Venezuela
}

\section{Resumen}

El presente ensayo tiene como objetivo considerar la necesidad de una teoría educativa que sea vista desde el paradigma de la complejidad para la formación de pensamiento crítico y complejo. Para lograrlo se parte, en un primer momento, de una exploración histórica del problema epistemológico, teniendo como inicio a los presocráticos y terminando con los psicopedagogos del siglo XXI. Luego, se toma en cuenta el surgimiento de la teoría crítica y cómo influyó en la necesidad de crear un pensamiento crítico dentro del sistema social y educativo; y por último, se tiene en consideración al paradigma de la complejidad desde Edgar Morín, y como ésta perspectiva considera necesaria la formación del pensamiento complejo y crítico en el proceso educativo contemporáneo.

Palabras clave: teoría educativa; pensamiento; epistemología. 


\title{
Educational Theory from the Paradigm of Complexity to form Critical and Complex Thinking
}

\begin{abstract}
The Present Test has as objective consider the need from an educational theory that is seen from the complexity paradigm for the formation of critical and complex thinking. In order to achieve this, in starts, at first, with a historical exploration of the epistemological problem, starting with the preSocratics and ending with the twentieth first-century psycho-pedagogues. Then, the emergence of critical theory is taken into account and how it influenced the need to create critical thinking within the social and educational system; and finally, the paradigm of complexity is taken into account since from Edgar Morin, and how this perspective considers the formation of complex and critical thinking in the contemporary educational process necessary.
\end{abstract}

Keywords: educational theory; thinking; epistemology.

Date Received: 20-02-2018

Date Acceptance: 12-04-2018 


\section{Introducción}

Desde la perspectiva histórica, se puede decir que el ser humano es un ser que constantemente vive transformándose y a su vez transformando su pensamiento y su entorno. Esta transformación la podríamos definir utilizando un término del naturalista inglés, Charles Darwin: evolución. Dicho término está enmarcado, en este ensayo, no en la apreciación de un cambio en herencia genética fenotípica sino más bien como una causa a la biodiversidad en cada nivel de la organización biológica, es decir, como una propiedad inherente a los seres vivos de buscar lo mejor, de desarrollarse con tal de lograr fines mayores.

Dentro de ese proceso evolutivo la historia humana ha vivido en una constante tensión y transformación entre el ser y el deber ser, dicha tensión hay que entenderla no como una complicación de la naturaleza humana, sino más bien como la comprensión de que el hombre es un ser complejo por naturaleza, que se encuentra en una situación, en una realidad y por ende, busca, tiende a algo más allá. En esa tensión se podría ubicar el proceso epistemológico y más aún, el proceso educativo, el cual debería tener como fin último, el crear pensamiento crítico. Además, dicho proceso hay que enmarcarlo dentro de la complejidad propia del ser humano.

Por tanto, teniendo como finalidad contribuir a la controversia educativa contemporánea intentando sintetizar y clarificar teoría del conocimiento, este ensayo tiene como propósito considerar la necesidad de una teoría educativa que sea vista desde el enfoque de la complejidad para la formación de pensamiento crítico y complejo.

Para lograr tal fin, se efectúa una breve indagación histórica del problema epistemológico, teniendo como inicio a los presocráticos y culmen a los psicopedagogos del siglo XXI con tal de entender, cuáles son sus características y su modo de proceder. Luego, se hará una consideración del surgimiento de la teoría crítica y cómo la misma influyó en la necesidad de 
crear un pensamiento crítico dentro del sistema social y educativo; y por último, se tiene en cuenta al paradigma de la complejidad desde Edgar Morín, y como ésta perspectiva considera necesaria la formación del pensamiento complejo y crítico en el proceso educativo contemporáneo.

\section{Desarrollo}

\subsection{Exploración histórica del problema epistemológico}

Haciendo una breve síntesis del problema, podríamos contextualizarlo dentro de tres grandes etapas: el problema en la antigüedad, en el medioevo y en la contemporaneidad. Con respecto al problema en la época antigua, resumiendo y parafraseando la obra de Fraile (1997a, págs. 1-10), se tiene lo siguiente:

a. El problema epistemológico tiene sus inicios en los presocráticos (año 624 a.C.), con Heráclito, Parménides, entre otros, los cuales fundamentaban que el hombre tiene un modo de saber fijo, estable, necesario.

b. Luego el problema de la ciencia entra en vías de solución con Sócrates, el cual, halla el verdadero camino del conocimiento científico al descubrir el concepto universal, la definición y el proceso inductivo para elaborarlos.

c. Platón marca un avance dentro de la complejidad epistemológica con la fundación de la academia (387 a.C.), en la cual el plan de estudio comprendía las tres ciencias fundamentales correspondientes con las tres clases de la sociedad: matemáticas (guerreros), artes mecánicas (artesanos) y la dialéctica, que era la ciencia suprema de las ideas transcendentales propia de los gobernantes.

d. Aristóteles y su Liceo, en el cual se da una parcialización del saber, dicha parcialización se da en tres grandes ramas: teoréticas, prácticas y poéticas; las cuales a su vez están conformadas por otras 
parcializaciones más concisas. Aunque para el liceo aristotélico la cumbre suprema del saber es el teológico, ya que versa sobre el objeto más elevado: Dios.

Ya avanzado un poco más en la historia de la humanidad, entramos en la época medieval, en la cual lo epistemológico se da dentro de lo filosófico y lo teológico. Vale acotar, que se da una distinción entre los órdenes del saber, racional y revelado, correspondiente a los órdenes ontológicos: el natural y el sobrenatural. En la cual la filosofía cumple una función de subordinación instrumental a la ciencia sagrada. Sin embargo, se hacen la excepción el "Doctor Universal", Alberto Magno, y el "Doctor Angelicus", Tomás de Aquino. Parafraseando a Fraile (1997b, págs. 10-19), se puede decir que:

a. San Alberto Magno mantiene una visión enciclopédica del saber, cultivando por igual las distintas ramas de la ciencia

b. Por su parte santo Tomas de Aquino conserva la misma visión integral y enciclopédica del saber que su maestro San Alberto. La distinción entre el saber racional y revelado no constituye una antítesis, sino un conjunto armónico y complementario.

Con respecto al momento de la modernidad, hay que decir que el siglo XIV comienza un proceso de desconfianza al concepto de ciencia. Surgiendo así el nominalismo, todo es nombre, los universales no existen, siendo la raíz del movimiento que poco más tarde dará origen al nacimiento de las ciencias experimentales, las cuales se definían como exactas y naturales. Se da un reauge de las parcializaciones del saber.

Adentrados en el siglo XIX y XX, el problema epistemológico adquiere nueva forma, surgen las teorías del aprendizaje con definiciones psicológicas y pedagógicas, las cuales describen los modos y formas en las que el hombre aprende. Dentro de esas teorías del aprendizaje cabe mencionar: 
a. El constructivismo: en el cual han aportado Piaget, Vygotsky y Ausubel. Dicha posición sostiene, como lo afirman Araya, Alfaro y Andonegui (2007): "el sujeto construye el conocimiento de la realidad, ya que ésta no puede ser conocida en sí misma, sino a través de los mecanismos cognitivos de que se dispone" (pág. 77), es decir, el constructivismo sostiene la importancia del sujeto en la adquisición del conocimiento, pues lo considera activo, el cual ha de construir o reconstruir el conocimiento a través de la acción. En definitiva, la idea central del constructivismo es que el aprendizaje se construye, el intelecto elabora nuevos conocimientos a partir de aprendizaje previos.

b. Conductismo: teoría educativa enmarcada dentro de la ciencia psicológica, tiene como fundador al estadunidense Watson. En palabras de Yela (1998): en su artículo la evolución del conductismo, éste "es el intento más ambicioso y tenaz de la historia de la psicología de construir un sistema científico estrictamente lógico y objetivo y el proyecto de mejorar con su aplicación, eficaz y comprobablemente, la conducta humana" (pág. 165). El conductismo, se aboca, por tanto, a la conducta y defiende la aplicación de procedimientos experimentales para estudiar dicho comportamiento. En cuanto al aprendizaje, estos los conciben "como la suma de un cúmulo de conductas aprendidas a través de la práctica y del constante reforzamientos de patrones y de conductas deseadas con lo cual se explica la concepción del aprendizaje como un hecho observable, medible y cuantificable" (Gudiño, 2011a, pág. 300). El sujeto, en esta teoría, juega por consiguiente una función pasiva, el aprendizaje va a responder a una serie de estímulos-respuestas y a su reforzamiento.

c. Cognitivismo, es una teoría fundamentada por Chomsky, Neisser, James y otros. Los cuales focalizan su teoría en la cognición, es decir, en los procesos relacionados con el conocimiento, en la manera en que 
el ser humano aprende. En la teoría cognitivista, como afirma Gudiño (2011b): "el aprendizaje es un proceso interno, cuya base fundamental estriba en la capacidad que tiene el individuo para asimilar y acomodar en las estructuras cognitivas los nuevos esquemas o nuevos repertorios de aprendizaje" (pág. 306). Por tal razón, en palabras de la autora, el aprendizaje es un proceso íntimo, intrínseco, el cual se logra por medio de unas estructuras cognitivas que se van adquiriendo y desarrollando conforme el individuo aprendiz se interrelaciona con el medio ambiente que lo rodea. En el cognitivismo el conocimiento es complejo, donde entra en relación las capacidades internas del sujeto y el medio donde se desenvuelve.

Una vez visto a grosso modo, el recorrido histórico que ha tenido el problema epistemológico, pasamos a considerar el surgimiento de la teoría crítica como una nueva forma epistemológica y cómo la misma influyó en la necesidad de crear un pensamiento crítico dentro del sistema social y por ende educativo.

\subsection{La teoría crítica y el pensamiento crítico}

La Teoría Crítica representó una ruptura epistemológica con respecto a la ciencia y filosofía tradicional, ruptura que se dio en los ámbitos intelectuales/académicos emblemáticos durante los primeros decenios del siglo XX y tiene su origen en la Escuela de Fráncfort en 1924. La misma tuvo una fuerte influencia marxista y como tal establece una crítica a las teorías tradicionales, al capitalismo y a la dominación. Entre sus teóricos más importantes se encuentran Horkheimer, Adorno, Habermas, Marcuse y Gadamer, los cuales consideraron a la teoría critica como una nueva visión de la filosofía, originariamente definida, en oposición a la filosofía y teoría tradicional, como afirma Frankenberg (2011): 
La teoría tradicional representa el tipo de teorización $<<$ Scientista >> guiadas por los ideales de las ciencias naturales modernas y su prerrogativa de investigaciones <<libres de valoración>>. Los autores de la teoría crítica parten de la asunción de que tanto los objetos observados como los sujetos observadores de la ciencia están constituidos socialmente $y$, por lo tanto, deben ser analizados $e$ interpretados dentro de su contexto histórico-social. (pág. 68).

En suma, la teoría critica, se posiciona en paralelo a la manera de teorizar que tradicionalmente se llevaba a cabo. Pues dichos autores consideraban que el contexto es fundamental en la ciencia, y no solo el fenómeno como tal. Con la teoría crítica se empleó una nueva visión de estudio con "cuya óptica analizaron con rara uniformidad la gran variedad de problemas teóricos, culturales y sociales que intentaron resolver" (Fraile, 1998a, pág. 106).

La teoría crítica como epistemología educativa "intentó retomar una nueva vía que restablezca la auténtica dimensión de la racionalidad" (Fraile, 1998b, pág. 108). La cual no debía ser tecnificada o utilitaria, sino que por el contrario debía ser autónoma y emancipadora.

En consecuencia, se considera que la teoría critica en definitiva es una crítica de la razón por parte de este movimiento, pues ellos consideraban que la razón había quedado instrumentalizada, "reducida a ser instrumento de ciertos fines que la desvían de su propio objeto del saber y la prostituyen, haciéndola servir a la dominación sobre los hombres" (Fraile, 1998c, pág. 108).

Para los precursores de la teoría crítica, como Adorno y Horkheimer, la razón instrumentalizada acarrearía consigo un pensamiento oscuro e irregular, el iluminismo. Por ende, se propusieron definir a la razón como una <<crítica >>, y el pensamiento ya no es oscuro, sino que es considerado polémico y crítico, capaz de analizar y refutar, quedando el conocimiento como una <<mediación>>, "una imagen o copia de las cosas" (Fraile, 1998d, pág. 
108).

La teoría critica en definitiva quería recuperar el concepto de la razón, por tal motivo, como nueva epistemología consideraron la necesidad de construir en la sociedad un tipo nuevo de pensamiento que rompiera con las viejas estructuras de la filosofía (iluminismo), este pensamiento se llamó: pensamiento crítico, el cual es definido siguiendo a Saladino (2012): como "todo planteamiento intelectual producto de análisis, interpretaciones y problematizaciones racionales acerca de las manifestaciones de la realidad, sus fenómenos, situaciones e ideas, para generar cuestionamientos, juicios y propuestas orientadas a la promoción de cambios en beneficio de la humanidad" (pág. 1).

En consecuencia, el pensamiento crítico se transforma en el método de la nueva perspectiva epistemológica surgidas a partir del siglo $\mathrm{XX}$, pues se busca con él "enfrentar" a la realidad, problematizarla, plantearse nuevas cuestiones, generar propuestas de progreso, donde el ser humano se cuestione hasta de su pensamiento, como dice Villarini (2003a): "es cierto que otros animales piensan, sólo el ser humano puede pensar su propio pensamiento. La metacognición es precisamente esta capacidad del pensamiento para examinarse, criticar y ajustar el proceso de pensamiento tanto en sus destrezas, conceptos y actitudes" (pág. 37), en otros términos, la capacidad crítica que tiene el ser humano lo lleva a repensar su manera de pensar, a evaluarse y examinarse a sí mismo, todo esto con el fin de que el hombre no se quede en mitos cognitivos, sino que se transforme en un ser emancipado, libre de ataduras y capaz de cuestionar a la realidad.

El mismo Villarini (2003b): afirma que la metacognición es la causa para un pensamiento crítico, cuando ésta "se lleva a cabo desde cinco perspectivas críticas, que a lo largo de la historia los seres humanos han ido creando para examinar y evaluar el pensamiento, el pensamiento se eleva al nivel crítico" (pág. 40), dichas perspectivas son la lógica, la sustantiva, la contextual, la 
dialógica y la pragmática, todas confluyen en la capacidad de examinar el pensamiento.

Llegados a este punto, donde de manera general se consideró las definiciones de teoría crítica y sus principios básicos, surgen dos cuestiones: ¿Cómo es comprendido el problema epistemológico en la actualidad (mitad del siglo XX en adelante)? ¿Ayudará al que hacer educativo incentivar a la formación de pensamiento crítico desde una perspectiva de la complejidad? ¿Será necesaria una teoría educativa que tenga la óptica de la complejidad para así ayudar en la formación de pensamiento crítico y complejo?

He aquí que, para responder a dichas cuestiones, se podrá considerar la postura del filósofo y sociólogo francés Edgar Morín, el cual, con su Teoría De La Complejidad, busca dar una respuesta acertada al problema planteado, pues como afirma Gómez (2010): "es un nuevo paradigma científico generalizador, capaz de abarcar a todas las ciencias" (pág. 2).

\subsection{El pensamiento complejo dentro del proceso educativo actual}

Edgar Morín para considerar el problema epistemológico considera primeramente el problema antropológico. Dicho problema lo evalúa, lo considera, lo estructura en sus primeros años de investigación científica, y es en el año de 1951, con su obra El Hombre y La Muerte, que considera "al hombre como un ser total, individuo, especie, sociedad" (Morín, citado por Gómez, 2003a, pág. 11).

Por tanto, se puede considerar que Morín tiene una visión holística del hombre. Lo considera ya no como un homo fabe u homo sapiens sino como un homo complexus, como afirma Gómez (2003b): "el hombre se ha vuelto <omnívoro> frente al mundo, abierto a toda la realidad. Él mismo es un microcosmo, entregado a todas las participaciones en el macrocosmos" (pág. 12). El hombre, en definitiva, es un ser complejo que lleva inmerso los caracteres antagónicos, pues su totalidad es fruto de su omnivoralidad, 
"devora", asume todo. La complejidad del hombre está asumida por todo lo que el hombre es, hace, vive y experimenta.

Al considerar al hombre como un ser complejo, hay que considerar también así su modo de aprender. El proceso educativo, es decir, su manera de adquirir conocimiento hay que considerarlo no solo como un condicionamiento o como un constructo, sino como un proceso complejo, el cual debe fomentar una inteligencia multidimensional, capacitada en un conocimiento general y global.

Morín propone necesario un pensamiento complejo y por ende, un pensamiento crítico, el cual puede referirse al ámbito educativo. Dicho pensamiento lleva necesariamente a considerar a la realidad por sí misma como compleja, donde el pensamiento, como afirma Morín (1990a): "debe afrontar lo entramado de la solidaridad de los fenómenos entre sí, la contradicción" (pág. 33).

Por tal motivo, el pensamiento al igual que el proceso educativo no debe conformarse, como manifiesta Morín (1990b): solo "con el paradigma de disyunción/reducción/unidimensionalización, sino que debe ser sustituido por un paradigma de distinción/conjunción que permita distinguir y asociar" (pág. 34). Considerar la realidad como compleja, lleva necesariamente a decir que la misma no puede simplificarse, sintetizarse, definirse en una sola dimensión. Por tanto, la realidad al ser multidimensional y compleja puede y debe sustentar un pensamiento que tenga sus propias características: complejocrítico y multidimensional.

Simplificar la realidad y por ende parcializar el saber es fruto de la ciencia contemporánea. A raíz de ésta, se consideraba solo una arista de la realidad, la cual al ser sometida al paradigma disyunción-reducción, queda reducida a una sola dimensión. Sin embargo, una emergente racionalidad, una nueva epistemología, expresada bajo el término complejidad, surgida a mediados del siglo XX, viene relegando dicha simplificación, devolviéndole al 
cosmos el valor que realmente posee: el entramado de su ser (la complejidad) y la multidimensionalidad.

Dicho paradigma busca articular, como afirma Morán (2006a): "Ios parcelamientos disciplinarios, quebrados por el pensamiento disgregador, a fin de construir un conocimiento multidimensional que se oponga a la supremacía de una ciencia sobre cualquier otra, a una omniracionalidad" (pág. 4). Por tal razón, el nuevo paradigma propuesto por Morín, busca la conexión y la interrelación de todos los saberes. El paradigma de la complejidad busca que se miren todas las aristas del polígono (realidad) y a su vez, vincularlas todas para la formación de un conocimiento, el cual por su misma ontología y principio será complejo.

Esto lleva necesariamente al reconocimiento de todas las entidades participantes en la gestación del conocimiento, distinguiéndola pero no aislándola, sino por el contrario vinculándolas. No es necesario mutilar el conocimiento y desfigurar la realidad. De acuerdo con esto, Morín (1990c): expresa que el pensamiento complejo, "está animado por una tensión permanente entre la aspiración a un saber no parcelado, no dividido, no reduccionista, y el reconocimiento de lo inacabado e incompleto de todo conocimiento" (pág. 23). Este nuevo enfoque apunta a una nueva realidad en el mundo epistemológico: el conocimiento no es total ni definitivo, sino progresivo.

En consecuencia, el conocimiento debe ser global, no es necesaria ya las divisiones fronterizas. Queda claro que la omnisciencia no es posible, sin embargo, como manifiesta Morín (1990d): "el pensamiento complejo aspira al conocimiento multidimensional... uno de los axiomas de esta propuesta epistemológica es la imposibilidad, incluso teórica, de una omnisciencia" (pág. 23).

Todo esto induce a la no parcialización del conocimiento bajo ningún dogma científico o filosófico, pues hacerlo significa mutilar el conocimiento y 
desfigurar a la realidad. En consecuencia, toda forma de comprender a la realidad y al conocimiento, debería reconocer y ponderar tanto a la naturaleza como al sujeto. Con el nuevo paradigma, propuesto por Morín, "se trata de un punto de vista que cuenta con el mundo y reconoce al sujeto. Más aún, la epistemología de la complejidad presenta a uno y otro de manera recíproca e inseparable" (Morín 1990e, pág. 64). De la cita anterior se deduce entonces, que el nuevo paradigma presenta un equilibrio entre realidad y sujeto, y no se dará ponderación únicamente a la subjetividad del sujeto o solo a la objetividad de la realidad, en cambio habrá una relación recíproca entre ambos.

El nuevo paradigma permite, como afirma Morán (2006b): criticar la epistemología occidental, surgida a raíz de la modernidad, fundada sobre la eliminación positivista del sujeto a partir de la idea de que los objetos, al tener existencia independiente del sujeto, eran observables y oportunamente explicados en tanto tales (pág. 4).

Es decir, en occidente el conocimiento se sustenta sobre la realidad, pero a partir de la modernidad se deja a un lado al sujeto, rompiendo así, la premisa medieval, de que el conocimiento es una aprehensión de la realidad, en la cual juega un papel activo tanto la realidad como el sujeto. Por tanto, el paradigma de la complejidad, lo que quiere es retomar un tanto la premisa de los medievales como Tomás de Aquino, donde el conocimiento es complejo, por lo cual, hay dos factores importantes para la construcción del mismo: sujeto y realidad, sin ponderar a uno sobre el otro, para no caer en los extremos del idealismo o empirismo.

En definitiva, el sujeto cognoscente no es pasivo, sino activo, pero su manera de conocer no ha de ser parcializada sino ampliada, donde se tomen en cuenta no solo lo que se quiere aprender, sino como se quiere aprender, y la realidad desde donde se quiere aprender. Ya no es mito, ya no es solo una razón instrumentalizada, sino que la razón juega un papel de actividad para 
formar un pensamiento crítico, donde no acepta la verdad como dogma impuesto sino la verdad que ha sido refutada, "masticada" y digerida. La complejidad necesariamente me lleva a la "criticidad".

Ser crítico, es comprender la complejidad de la realidad, es no quedarse con una sola perspectiva. Es la no aceptación de un dato sin antes éste no ser mirado desde distintos enfoques, pues así el pensamiento no es mutilado, sino por el contrario ampliado. Morín entiende al mundo como una red, donde todo está vinculado, por consiguiente, la manera de afrontarlo debe ser multidisciplinar y a su vez, multirreferenciado. Esto lleva a tener como consecuencia lógica, la formación de un pensamiento crítico, el cual "hace referencia a ejercicios de cuestionamiento y de valoración, que nos permitan finalmente emitir un juicio o tomar una posición con respecto a un hecho, a un fenómeno o a una idea" (Morales, 2014, pág. 3).

El proceso educativo actual requiere, por tanto, forjar hombres capaces de tener una búsqueda constante por la verdad, una inclinación natural por el saber, esto demanda afrontar un contenido, un dato, cuestionarlo y valorarlo, de manera que la comprensión de dicho dato, le ayude a tomarlo como cierto o no, de ese modo, el estudiante estará formando pensamiento complejo y crítico, y no solo conocimiento "condicionado", como respuesta a un estímulo.

Bien se sabe que el paradigma de la complejidad admite la imposibilidad de conocer todo de todo, sin embargo, el mismo admite que es posible conocer bastante de todo. Pero para que esto ocurra, es necesario en la formación, que el estudiante cuestione la realidad, se pregunte el porqué de las cosas. Así este nuevo paradigma luce como una opción para transformar el proceso educativo, acentuando el papel activo del estudiante y de la realidad. Todo es un complejo, tanto la razón como todo aquello que rodea al sujeto.

\section{Conclusiones}

La teorización de la educación debe platearse como objetivos y metas: 
la misión de incentivar la formación de pensamiento crítico y complejo. Estamos ante un mundo complejo, por tanto, nuestro modo de pensar no debe ser ni parcializado ni dogmatizado, más bien, debe ser crítico y ampliado, donde nos preguntemos por las cuestiones últimas y primeras de la realidad.

La práctica docente no debe quedarse en una mera repetición de contenido, en un dictamen de teoría, antes bien, debe desarrollar en los educandos la capacidad de razonar y que ellos mismos creen y formen un pensamiento crítico, es decir, sean capaz de examinarse y evaluarse a sí mismo y al entorno que les rodea, esto los llevará a adquirir un conocimiento complejo, estructurado y sistematizado.

La misión fundamental que ha de tener el educador del siglo XXI, no es únicamente en ser transmisores de conocimientos, antes se debe ayudar a los estudiantes a formar su propia criticidad, donde la crítica no sea considerada en su concepción peyorativa, es decir, reprobación y censura, sino en su concepción elogiosa, la crítica como un establecimiento de juicio y toma de decisiones. El educando de hoy, requiere docentes capaces de enseñar en ellos dicha capacidad, así lograrán formar un pensamiento complejo, donde puedan articular todas las aristas del polígono llamado realidad.

Es menester, por lo tanto, se debe tener presente en las teorías educativas actuales, como una de las propuestas que Morín recomienda, la cual ha de ser una norma fundamental en el proceso educativo hoy, "todo conocimiento opera mediante la selección de datos significativos y rechazo de datos no significativos" (Morín, 1990f, pág. 28). El proceso de aprendizaje se fundamenta en esa premisa, el educando quiere datos que le digan algo, que le sea significativo.

Es así, donde el estudiante comprenderá que es sujeto activo en su proceso formativo y no pasivo, y de seguro tendrá la intención de aprender y desarrollarse. 


\section{Referencias}

Araya, V., Alfaro, M., y Andonegui, M. (2007). Constructivismo: Orígenes y

Perspectivas. Revista de educación Laurus, 13(24), págs. 76-92. ISSN: 1315-883X. Caracas, Venezuela: Universidad Pedagógica Experimental Libertador.

Fraile, G. (1997a,b). Historia de la Filosofía. Grecia y Roma. Tomo I. Madrid, España: Editorial B.A.C., págs. 1-19.

Fraile, G. (1998a,b,c,d). Historia de la Filosofía. Siglo XX: Neomarxismo. Estructuralismo. Filosofía de Inspiración Cristiana. Tomo VIII. Madrid España: Editorial B.A.C., págs. 102-170.

Frankenberg, G. (2011). Teoría Crítica. Revista sobre enseñanza del derecho, 9(17), págs. 67-84. ISSN: 1667-4154. Buenos Aires, Argentina: Rubinzal-Culzoni Editores.

Gómez, P. (2003a,b). La antropología compleja de Edgar Morín. Granada, España: Editorial Universidad de Granada, págs. 6-160.

Gómez, T. (2010). El nuevo paradigma de la complejidad y la educación: una mirada histórica. Revista Latinoamericana Polis, núm. 25. ISSN: 0718-6568. [En línea]. Recuperado de: https://polis.revues.org/400

Gudiño, D. (2011a,b). El conductismo y el cognoscitivismo. Dos entramados psicológicos de aprendizaje del siglo XX. Revista ciencias de la educación. Segunda Etapa, 21(38), págs. 297-308. ISSN: 1316-5917. Valencia, Venezuela: Editora, Facultad de Ciencias de la Educación de la Universidad de Carabobo.

Morán, L. (2006a,b). De la teoría de la complejidad a la filosofía intercultural: hacia un nuevo saber. Revista de Filosofía, 24(52), págs. 1-16. ISSN: 0798-1171. Venezuela: Universidad del Zulia.

Morales, L. (2014). El Pensamiento Crítico en la Teoría Educativa Contemporánea. Revista: Actualidades Investigativas en Educación, 14(2), págs. 1-23. ISSN: 1409-4703. Costa Rica: Universidad de Costa 
Rica.

Morín, E. (1990a,b,c,d,e,f). Introducción al Pensamiento Complejo. Barcelona, España: Editorial Gedisa, págs. 1-160.

Saladino, A. (2012). Pensamiento Crítico. Instituto de investigaciones sociales. México: Universidad Nacional Autónoma de México, págs. 110.

Villarini, A. (2003a,b), Teoría y pedagogía del pensamiento crítico. Revista Perspectivas psicológicas, volúmenes 3-4, año iv, Edición especial, págs. 35-42. ISSN: 1992-5131. República Dominicana, Universidad Autónoma de Santo Domingo.

Yela, M. (1998). La Evolución del Conductismo. Revista Psicothema, 8(suplem 1), págs. 165-186. ISSN: 0214-9915. España: Editorial Universidad de la Rioja. 


\section{Ángel Yasmil Echeverría Guzmán}

e-mail: angelecheverria71@gmail.com

Nacido en el Estado Bolivariano de Miranda,

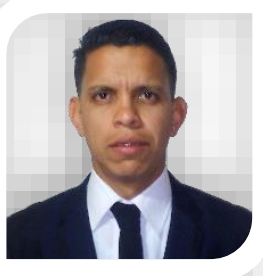
Venezuela. Residenciado en Charallave, Estado Bolivariano de Miranda. Técnico Superior en Educación, Mención: Artes Industriales y Profesor en Educación, mención: Artes Industriales del Instituto Universitario Monseñor Rafael Arias Blanco (IUPMA); Licenciado en Filosofía de la Universidad Católica Santa Rosa (UCSAR); Magister Scientiarum en Educación Técnica del Instituto Universitario Monseñor Rafael Arias Blanco (IUPMA); Doctorante del programa Ciencias de la Educación de la Universidad Latinoamericana y del Caribe (ULAC); Docente Instructor de la Universidad Nacional Experimental Politécnica "Antonio José de Sucre" (UNEXPO). 